\title{
The Action of Lysozyme on Bacterial Electron Transport Systems
}

\author{
By S. B. SHAH AND H. K. KING \\ Biochemistry Department, The University of Liverpool
}

(Received 12 October 1965)

\begin{abstract}
SUMMARY
Oxidation of several substrates by whole or broken organisms of Micrococcus lysodeikticus was arrested following treatment with lysozyme, unless an osmotic stabilizer (sorbitol) were present. Whole organisms, which did not oxidize $\mathrm{NADH}_{2}$, and broken organisms (which oxidized $\mathrm{NADH}_{2}$ only slowly) oxidized $\mathrm{NADH}_{2}$ readily after lysozyme treatment, though the activity was maintained only in presence of an osmotic stabilizer. Lysozyme treatment similarly allowed whole or broken $\boldsymbol{M}$. lysodeikticus to oxidize (mammalian) cytochrome $c$, or to reduce this cytochrome with appropriate electron-donors, e.g. lactate, succinate, or $\mathbf{N A D H}_{2}$. Most of these observations held good also for the lysozyme-sensitive Bacillus megaterium, but not for several lysozyme-insensitive organisms (both Gram-positive and Gram-negative).
\end{abstract}

\section{INTRODUCTION}

Protoplasts formed by lysozyme treatment of sensitive bacteria in presence of an osmotic stabilizer may retain the respiratory activity of the whole organisms; but lysis of the protoplasts by osmotic shock or lysozyme treatment of bacteria in absence of a stabilizer may severely decrease the ability of the bacteria to oxidize common substrates. This has been shown for Bacillus subtilis (Wiame, Storck, \& Vanderwinkel, 1955); B. megaterium (Weibull, 1953) and Micrococcus lysodeikticus (Pandya, 1963). The present paper describes an examination of the nature of the damage suffered by the respiratory enzyme systems.

\section{METHODS}

Organisms. The following bacteria were obtained from the National Collection of Industrial Bacteria: Micrococcus lysodeikticus, NCTC 2665 and Bacillus megaterium, NCIB 8291. The remainder were stock laboratory strains designated by our own numbers; Escherichia coli, E 106; B. subtilis, E 4 ; Sarcina lutea, E 7; Proteus vulgaris, L 10; Pseudomonas pyocyanea (aeruginosa), L 15. Organisms were maintained on nutrient agar slopes, grown in nutrient broth (Oxoid No. 2 : Lab-Lemco beef extract, $1 \%$; peptone, $1 \% ; \mathrm{NaCl}, 0.5 \%$; in tap water) at $32-34^{\circ}$ on a rotary shaker and at the end of the logarithmic phase ( $48 \mathrm{hr}$ for $\boldsymbol{M}$. lysodeikticus; overnight for other organisms) were harvested by centrifugation, washed twice on the centrifuge with distilled water; then suspended in water or buffer and stored at $4^{\circ}$ till required. Suspensions of organisms were normally used the same day though the lysozyme

Vol. 43, No. 3, was issued 19 July 1966 
sensitivity of $\boldsymbol{M}$. lysodeikticus did not alter appreciably on storage for several days at $0^{\circ}$.

Turbidimetry. Concentrations of bacterial suspensions were estimated (without filter) in the EEL portable colorimeter (Evans Electroselenium Ltd., Halstead, Essex) and converted to equivalent mg. dry wt. organism $/ \mathrm{ml}$. by using factors based on dry weight (air-drying at $\mathbf{8 0}^{\circ}$ ). The EEL colorimeter was also used for following changes in extinction during treatment with lysozyme and the results are recorded in terms of the scale readings of this instrument. (A reading of 3 corresponds to about $50 \%$ transmittance in a $1 \mathrm{~cm}$. cuvette.)

Sonic disintegration. Bacteria were disintegrated in small batches $(5 \mathrm{ml}$.) in a 60-W. 20-Kcyc./sec. M.S.E. sonic disintegrator with the large (18 mm. diam.) probe; temperatures were maintained below $+5^{\circ}$ by means of an ice-bath.

Materials. Crystalline lysozyme chloride, from egg-white (Koch-Light Laboratories Ltd., Colnbrook, Bucks.); reduced nicotinamide adenine dinucleotide $\left(\mathrm{NADH}_{2}\right)$; and mammalian cytochrome $c$ as $1 \%$ solution, about $\mathbf{7 0} \%$ oxidized, $\mathbf{3 0} \%$ reduced (Boehringer Corporation (London) Ltd.). Other reagents were commercial products. Ubiquinone-O was a gift from Messrs Hoffmann-La Roche, Basel, Switzerland, through the courtesy of Dr O. Isler.

Buffer. Unless otherwise stated enzyme experiments were done in a mixture of $\mathrm{Na}_{2} \mathrm{HPO}_{4}$ and $\mathrm{KH}_{2} \mathrm{PO}_{4}$, the total phosphate concentration $0.067 \mathrm{M}$, at $\mathrm{pH} 7 \cdot 4$.

Succinoxidase was measured by recording the oxygen uptake in Warburg manometers at $37^{\circ}$, in presence of $0.05 \mathrm{M}$-succinate, with $\mathrm{KOH}$ in the centre wells. In most experiments succinate was included in the main flask and manometric measurements began after $10 \mathrm{~min}$. equilibration; lysozyme or other additions were added from the side-bulb.

$\mathrm{NADH}_{2}$ oxidase was measured by the decrease in extinction at $340 \mathrm{~m} \mu$ at room temperature $\left(19-\mathbf{2 0}^{\circ}\right)$. Reference and experimental cuvettes contained (in $3 \mathrm{ml}$. buffer): organism (equiv. $1 \mathrm{mg}$. dry wt.) and lysozyme (at stated concentration). After the interval of time required for lysozyme action $\mathrm{NADH}_{2}\left(7 \cdot 5 \times 10^{-5} \mathrm{M}\right)$ was added to the experimental cuvette, a corresponding volume of buffer being added to the reference cuvette. The cuvettes were placed in a recording spectrophotometer (Unicam Ltd., SP-700) set at constant wavelength $(340 \mathrm{~m} \mu)$. The $\mathrm{NADH}_{2}$ oxidase activity was calculated from the steady initial decrease in extinction which was recorded over a period of 1-5 min. The molar extinction coefficient was taken as 6220 (Horecker \& Kornberg, 1945). Any decrease in extinction of the cell material itself resulting from the action of lysozyme was compensated for by the presence of organisms and lysozyme in the reference cuvette. It was, nevertheless, possible that spurious 'oxidation' of $\mathrm{NADH}_{2}$ might be recorded if the latter itself were to affect the rate of action of lysozyme on the bacteria. This, however, is not the case, since when the system was set up for measurement of $\mathrm{NADH}_{2}$ oxidase but the spectrophotometer set for $450 \mathrm{~m} \mu$ (at which wavelength there was no change in extinction arising from oxidation of $\mathrm{NADH}_{2}$ ) the instrument recorded a zero trace. Lysozyme alone did not cause any oxidation of reduced $\mathrm{NADH}_{2}$.

Cytochrome oxidase activity was measured by observing the decrease in extinction at $550 \mathrm{~m} \mu$ in presence of cytochrome $c$ and bacterial preparations; the details are given in the legends to the figures. No changes in extinction were observed when the 
spectrophotometer was set at $500 \mathrm{~m} \mu$, an isosbestic point for oxidized and reduced cytochrome.

Electron transfer from lactate, succinate or $\mathrm{NADH}_{2}$ to cytochrome $c$ in Micrococcus lysodeikticus was followed by the increase in extinction at $550 \mathrm{~m} \mu$ in presence of 0.007 M-cyanide which completely inhibited aerobic oxidation of these electron-donors in this organism; details are given in the legend to Fig. 7. The decrease in molar extinction coefficient at $550 \mathrm{~m} \mu$ on oxidation of cytochrome $c$ was taken as 19,700 (Hogeboom \& Schneider, 1952). Electron transfer from $\mathbf{N A D H}_{2}$ to ubiquinone-O and menaquinone-O (vitamin $\mathrm{K}$ ) was examined by setting up reference and experimental cuvettes containing (in $3 \mathrm{ml}$. buffer); organism, equivilent 5.4 mg. dry wt./ml.; KCN, 0.007 M; ubiquinone-O or menaquinone-O $\left(6 \times 10^{-5}\right.$ M). $\mathrm{NADH}_{2}$ was then added to the experimental cuvette only, and the rate of decrease in extinction at $340 \mathrm{~m} \mu$ determined. To investigate the effect of lysozyme, $30 \mu \mathrm{g} . / \mathrm{ml}$. were added to experimental and reference cuvettes at the desired time before the addition of $\mathrm{NADH}_{2}$.

Enzyme activities are expressed in international units/g. dry wt. of organism; 1 I.U. is the amount of enzyme which will transform $1 \mu$ mole of substrate/minute. For this purpose, the electron donor was regarded as the 'substrate' in all oxidationreduction systems.

\section{RESULTS}

\section{Lysis of Micrococcus lysodeikticus by lysozyme}

Figures $1 a, b$ show the percentage decrease of the extinction of a suspension of organisms following addition of lysozyme at $20^{\circ}$ and $37^{\circ}$. At $37^{\circ}$ lysis was about 60-70\% complete within 5 min., and the extinction reaches its terminal value (10-15\% of the initial value) after about $20 \mathrm{~min}$. The decrease in extinction in

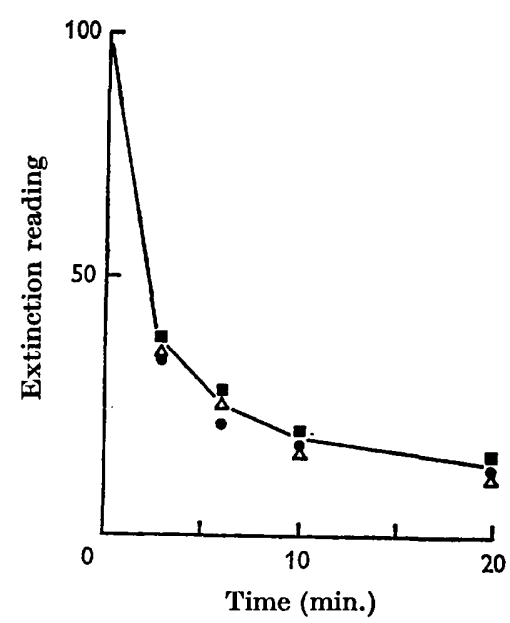

(a)

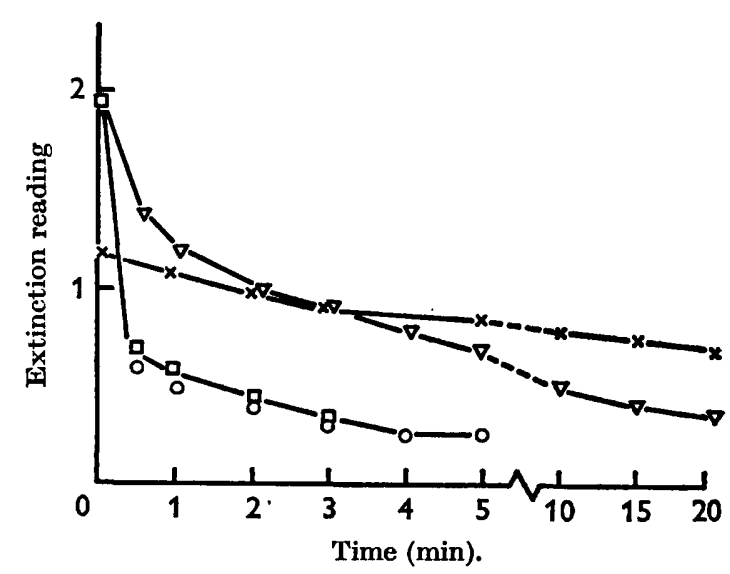

(b)

Fig. 1. Decrease in extinction reading of suspensions of Micrococcus lysodeikticus on treatment with lysozyme $(a) 37^{\circ}$, lysozyme $1.6 \mu \mathrm{g} . / \mathrm{ml}$.; $\square$ in buffer, $\bullet$ in buffer $+0.05 \mathrm{M}$ succinate. $\triangle$ in buffer +0.05 M-succinate, shaken in Warburg manometer. $(b)$ at $20^{\circ}$; $\nabla$, lysozyme, $0.33 \mu \mathrm{g}$. $/ \mathrm{ml}$.; $\times$ lysozyme $0.33 \mu \mathrm{g} . / \mathrm{ml}$. with $1.5 \mathrm{M}$-sorbitol; $\square$, , lysozyme $20 \mu \mathrm{g} . / \mathrm{ml}$., two separate experiments on different days. 
presence of sorbitol was substantially less, and represents the difference between the intact organisms with their highly-refractile cell walls and the poorly refractile protoplasts. The course of the reaction was essentially as described by Weibull (1953) for Bacillus megaterium. We chose sorbitol as an osmotic stabilizer because, unlike sucrose, it is not metabolized at a significant rate by the organisms studied. Polyethyleneglycol did not protect $\boldsymbol{M}$. lysodeikticus against lysis save at concentrations which gave excessively viscous solutions; $\mathrm{NaCl}$ was avoided because at concentrations adequate for osmotic stabilization it is itself an inhibitor of lysozyme action (Weibull, 1956).

Before decrease in extinction could be accepted as an index of lysis (in absence of sorbitol) it was necessary to decide at what stage actual lysis of the organisms occurred. Are some organisms rapidly lysed and others slowly, or does the progressive decrease in extinction represent a gradual removal of cell-wall material from all the organisms simultaneously? This was examined by treating organisms with lysozyme for different periods and then arresting both lysis and the action of the enzyme by adding $\mathrm{M}-\mathrm{NaCl}$. Surviving organisms and debris arising from lysis were centrifuged down $(100,000 \mathrm{~g}$ for $30 \mathrm{~min}$.) and nucleic acid in the clear supernatant fluid determined by extinction measurements at $260 \mathrm{~m} \mu$. Release of nucleic acid into the supernatant fluid ran closely parallel with the decrease in extinction of the suspension. Since little, if any, nucleic acid is present in the cell wall (Salton, 1953), we felt justified in using the decrease in extinction as a criterion of lysis in suspensions which did not contain an osmotic stabilizer.

\section{Action of lysozyme on succinate and fumarate oxidations}

Figures $2 a, b$ show the effect of lysozyme on oxidation of succinate and fumarate. Comparison with Fig. 1 shows that respiration did not stop immediately on lysis; 5 min. after adding lysozyme (when lysis was about $70 \%$ complete) the respiration had not begun to decrease. Appreciable decrease in oxygen uptake was seen only after $10 \mathrm{~min}$., when the extinction had already almost reached its final value. The situation was essentially similar with the oxidation of lactate. The possibility was considered that lysis might occur more slowly in the manometers than in the stationary tubes used for the extinction measurements; but when lysis was followed in shaken manometers in presence of succinate, the time-course was the same as in stationary tubes (Fig. $1 a$ ).

Sorbitol slightly retarded oxygen uptake, possibly because of a decreased diffusion of oxygen through the solution, but it protected the oxidation system against the action of lysozyme. When a system containing both lysozyme and sorbitol was diluted with buffer, thus causing lysis of the protoplasts, immediate arrest of succinate oxidation occurred (Fig. $2 a$ ).

Loss of enzyme activity was not due solely to disruption of the organisms. Sonic treatment for 5 min. disrupted about $80 \%$ of the organisms and increased succinate oxidase activity by some $20 \%$; but on treatment with lysozyme, there was a decrease in activity very like that obtained with whole bacteria. The succinate oxidase of the disintegrated preparation was likewise protected by sorbitol (Fig. 3). We considered the possibility that our lysozyme preparation was acting as an unspecific enzyme inactivator, but a commercial $\mathbf{N A D H}_{2}$-cytochrome $c$ reductase system, of mammalian origin, suffered no loss of activity on treatment with 
lysozyme at $17 \mu \mathrm{g} . / \mathrm{ml}$. Lysozyme has been reported to have no lipase, protease or amyolytic activity (Meyer, Palmer, Thompson \& Khorazo, 1936).

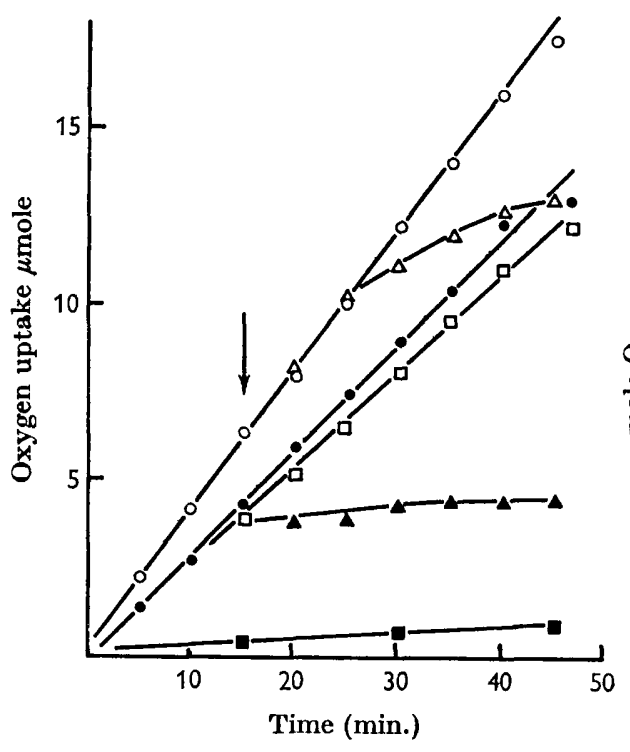

(a)

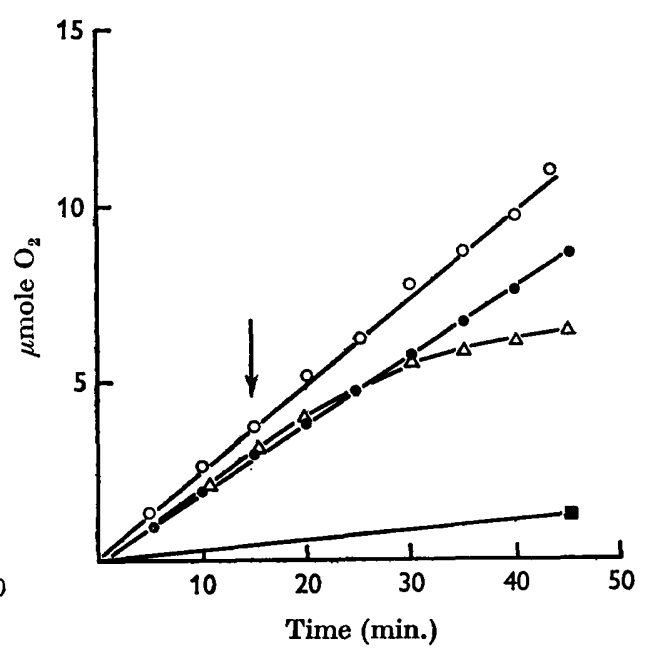

(b)

Fig. 2. Action of lysozyme on $(a)$ succinate and $(b)$ fumarate oxidation by suspension of Micrococcus lysodeikticus. Each manometer contained: equiv. $4 \mathrm{mg}$. dry wt. organisms suspended in $3 \mathrm{ml}$. buffer ( $\mathrm{NaOH}$ in centre cup), with the following additions; $\square$, none (no-substrate control); $O$, substrate (succinate or fumarate) $0.05 \mathrm{M} ; \Delta$, substrate with addition of lysozyme $1.66 \mu \mathrm{g}$. $/ \mathrm{ml}$. at $15 \mathrm{~min}$.; $\square$, substrate $+1.5 \mathrm{M}$-sorbitol; $\bigcirc$, substrate + sorbitol, addition of lysozyme $1.66 \mu \mathrm{g} . / \mathrm{ml}$. at $15 \mathrm{~min}$; $A$ substrate $+1.5 \mathrm{M}$-sorbitol + lysozyme in $3 \mathrm{ml}$; $1 \mathrm{ml}$. buffer added at $15 \mathrm{~min}$. to induce osmotic lysis.

\section{Activation of $\mathrm{NADH}_{2}$ oxidase in Micrococcus lysodeikticus}

Whole Micrococcus lysodeikticus organisms, like those of many other bacteria, are unable to oxidize $\mathrm{NADH}_{2}$ because of failure of the latter to obtain access to the enzyme sites within the organism. On sonic disintegration some degree of $\mathrm{NADH}_{2}$ oxidase activity was developed (of the order of 10 I.U./g. dry wt.), unless treatment were so severe as to inactivate the system. On treating a cell suspension of $M$. lysodeikticus with lysozyme (Fig. $4 a$ ) the $\mathbf{N A D H}_{2}$ oxidase activity developed rapidly, roughly parallel with lysis, and then decreased again as (presumably) the system was inactivated, either directly through the action of the lysozyme or as a result of the physical damage of lysis. On the other hand, in the presence of sorbitol a stable activity at about 100 I.U./g. was obtained. Similar results were obtained with broken organisms (Fig. $4 b$ ).

\section{Action of lysozyme on components of the electron transport chain}

Neither whole nor broken Micrococcus lysodeikticus oxidized mammalian cytochrome $c$. On adding lysozyme, in both cases slight oxidase activity was observed but ceased within a few minutes. However, on adding lysozyme to a preparation of micrococci suspended in $1.5 \mathrm{M}$-sorbitol in presence of cytochrome $c$, oxidation of the latter occurred at a rate of about 60 I.U./g. dry wt. (Fig. 5). With broken 
organisms lysozyme $\mathbf{0 \cdot 3 3} \mu \mathrm{g}$. $/ \mathrm{ml}$. (which causes relatively slow lysis) produced a gradual development of activity. When sufficient lysozyme $(20 \mu \mathrm{g} . / \mathrm{ml}$.) to produce rapid lysis was used, a high initial value of activity was obtained, followed by rapid inactivation of the system.

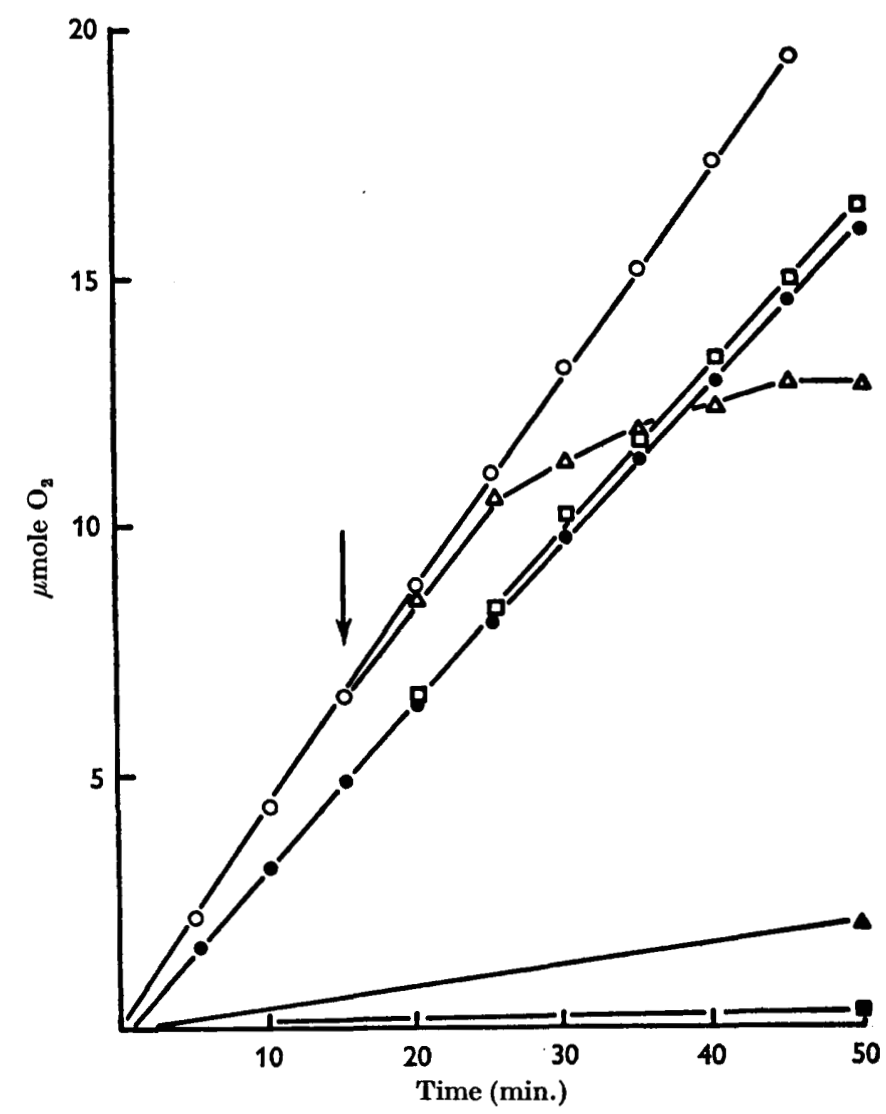

Fig. 3. Action of lysozyme on succinate oxidation by sonically broken Micrococcus lysodeikticus. Each manometer contained broken cocci equivalent to $4 \mathrm{mg}$. dry wt. in $3 \mathrm{ml}$. buffer (NaOH in centre cup) with the following additions; $\mathbf{n}$, none (no-substrate control); $\Delta, 1.5 \mathrm{M}$-sorbitol; $\bigcirc, 0.05 \mathrm{M}$-succinate; $\triangle, 0.05 \mathrm{~m}$-succinate with addition of lysozyme $\mathbf{1 . 6 6} \mu \mathrm{g} . / \mathrm{ml}$. at $15 \mathrm{~min}$.; $\square, 0.05 \mathrm{M}$-succinate $+1.5 \mathrm{M}$-sorbitol; $\bullet, 0.05 \mathrm{M}$-succinate + $1.5 \mathrm{M}$-sorbitol, with addition of lysozyme $1.66 \mu \mathrm{g} . / \mathrm{ml}$. at $15 \mathrm{~min}$.

Added cytochrome $c$ was not reduced by succinate, lactate or $\mathrm{NADH}_{2}$ in presence of whole or broken Micrococcus lysodeikticus. On adding lysozyme to whole organisms reduction of the cytochrome occurred with all three substrates (Fig. 6). In experiments in which micrococci (whole or broken) were treated with lysozyme $(20 \mu \mathrm{g} . / \mathrm{ml}$.) and the cytochrome $c$ reductase activity measured after various times relatively rapid destruction of the reductase system was observed.

Whole or broken Micrococcus lysodeikticus showed only low activity for oxidation of $\mathrm{NADH}_{2}$ by ubiquinone-O (2,3-dimethoxy-5-methyl-1, 4-benzoquinone) or by menaquinone-O (2-methyl-1,4-naphthaquinone: vitamin $K$ ) in a system in which aerobic oxidation was blocked by 0.007 M-cyanide; but on treating with lysozyme, 
$20 \mu \mathrm{g} . / \mathrm{ml}$., rapid oxidation took place. Though inactivation ultimately occurred, the system was considerably more stable in the presence of lysozyme than was the $\mathrm{NADH}_{2}$-cytochrome $c$ reductase system.

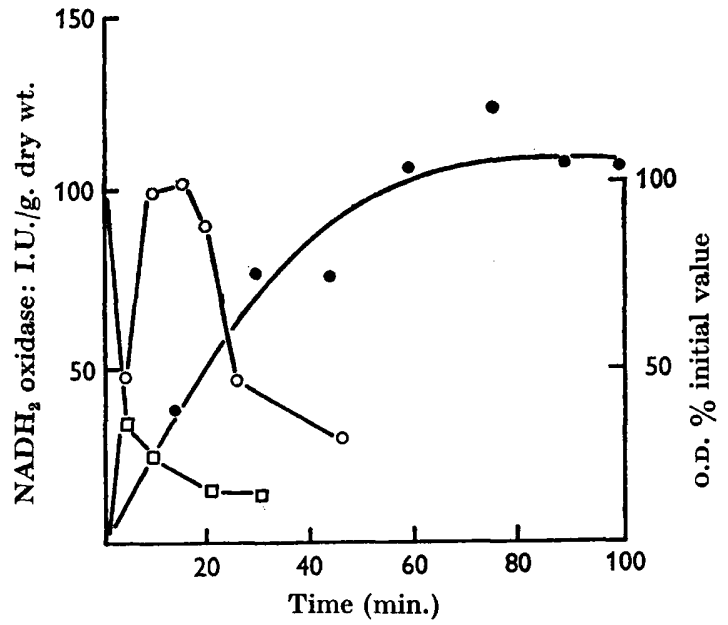

(a)

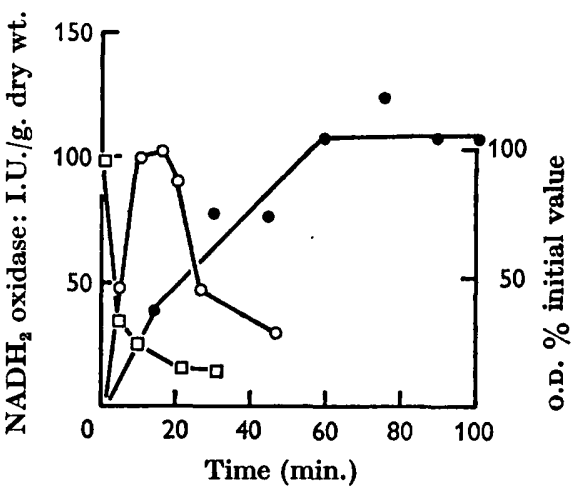

(b)

Fig. 4. Development of $\mathrm{NADH}_{2}$ oxidase in suspensions of (a) whole organisms, (b) broken organisms of Micrococcus lysodeikticus on treatment with lysozyme $0.33 \mu \mathrm{g}$./ ml. $O$, without sorbitol; $\bullet$, in $1.5 \mathrm{~m}$-sorbitol. $\square$, extinction reading of suspension (without sorbitol) expressed as \% of initial value.

\section{Bacillus megaterium : action of lysozyme on respiratory system}

Bacillus megaterium is lysozyme-sensitive but only at concentrations of lysozyme 50-100 times higher than required for Micrococcus lysodeikticus. The effect on succinate oxidation was very similar in the two organisms (Fig. 7) although the high endogenous respiration in $\boldsymbol{B}$. megaterium made interpretation of the results more difficult. Lysozyme treatment much increased the low $\mathrm{NADH}_{2}$ oxidase activity of intact B. megaterium, roughly pari passu with lysis. In absence of an osmotic stabilizer prolonged treatment with lysozyme inactivated the oxidase system of $B$. megaterium as in M. lysodeikticus; when lysis was prevented by sorbitol the system was more stable though the maximum activity attained is lower (Fig. 8). The $\mathrm{NADH}_{2}$ oxidase activity in sonically-broken material was about double that of whole $B$. megaterium, but was not appreciably increased by lysozyme. This was quite different from the results obtained with $M$. lysodeikticus (Fig. $4 b$ ), but the difference may be more apparent than real since concentrations of lysozyme in excess of those required to expose the enzyme systems may, in some cases, cause rapid inactivation. It was possible that in $B$. megaterium destruction of the enzyme occurred as rapidly as its release (see Fig. 8).

Neither whole nor broken Bacillus megaterium preparations oxidized (mammalian) cytochrome $c$; addition of lysozyme had little effect, any activity liberated being, presumably, rapidly lost. In presence of sorbitol, however, after some delay, a stable cytochrome oxidase activity was developed (Fig. 9). The delay may perhaps represent the time required to dissolve away cell wall down to the layers at which 
the external cytochrome $c$ can make contact with the enzyme systems. When these results are compared with the corresponding data for Micrococcus lysodeikticus, there are indications of a similar though less clear-cut lag when the lysozyme concentration used was sufficient to produce only a moderate rate of lysis (Fig. 5, curves $\mathbf{B}$ and $\mathbf{E}$ ).

The activation of the cytochrome $c$ reductase system of Bacillus megaterium by lysozyme is shown in Fig. 10. At a relatively high lysozyme concentration (50 $\mu \mathrm{g} . /$ ml.) broken bacilli developed reductase activity to a high value with very little lag; succinate, lactate or $\mathbf{N A D H}_{2}$ were equally effective as electron donors. The system was stable even in absence of sorbitol. With less lysozyme $(20 \mu \mathrm{g} . / \mathrm{ml}$. $)$ the activity was much lower and there were marked differences between the electron donors; curiously, $\mathrm{NADH}_{2}$ gave a higher activity than lactate or succinate. Whole bacilli developed cytochrome $c$ reductase activity only relatively slowly on treatment with lysozyme, and to a much lower degree than was attained with lysozyme-treated broken cell preparations.

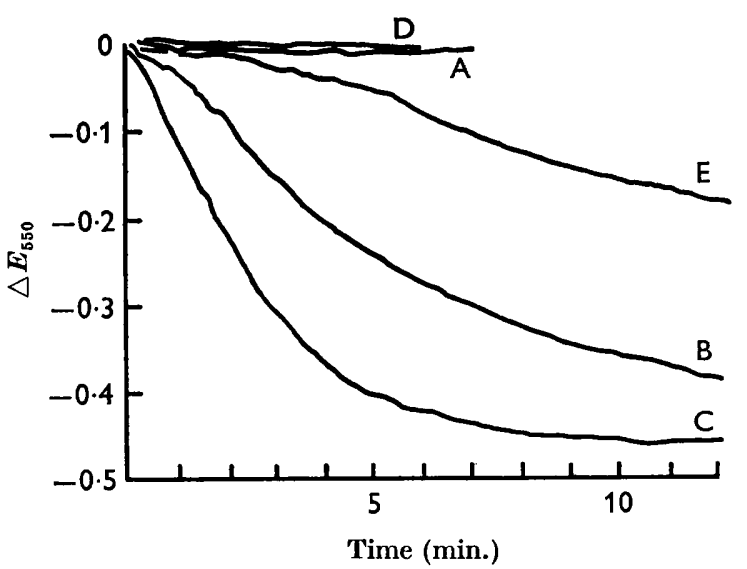

Fig. 5

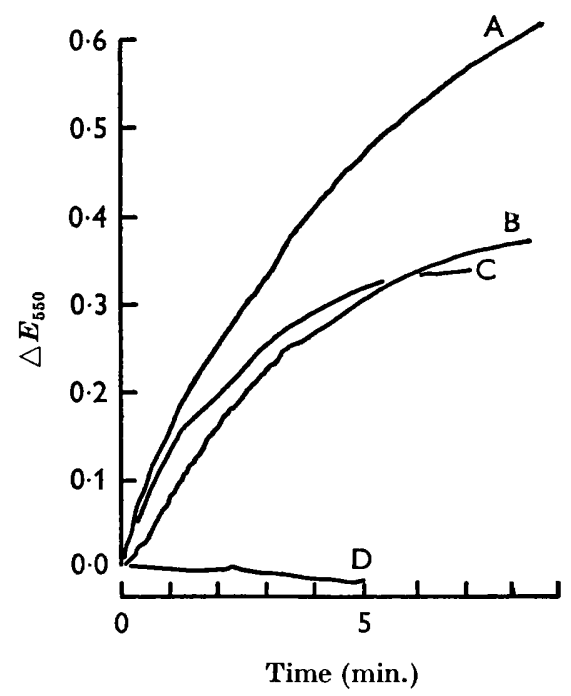

Fig. 6

Fig. 5. Release of cytochrome oxidase activity in Micrococcus lysodeikticus by Iysozyme. Reference and experimental cuvettes contained equivalent of $0 \cdot 27 \mathrm{mg}$. dry wt. of organisms $/ \mathrm{ml}$. in $1.5 \mathrm{M}$-sorbitol; $2 \mathrm{mg}$. cytochrome $c$ in experimental cuvette only. Lysozyme added to both cuvettes at $0 \mathrm{~min}$. Oxidation of cytochrome followed by decrease in extinction at $550 \mathrm{~m} \mu$. Experiments with whole organisms in presence of $1.5 \mathrm{M}$-sorbitol; A, control, no lysozyme; B, lysozyme $0 \cdot 33 \mu \mathrm{g} . / \mathrm{ml}$.; C, lysozyme $20 \mu \mathrm{g} . / \mathrm{ml}$. Experiments with broken bacteria in presence of $1.5 \mathrm{M}$-sorbitol; $\mathrm{D}$, control, no lysozyme; $\mathrm{E}$, lysozyme $0.33 \mu \mathrm{g} . / \mathrm{ml}$. No change in extinction occurs when cytochrome is treated with lysozyme in absence of the organism.

Fig. 6. Development of electron transfer for lactate, succinate or $\mathrm{NADH}_{2}$ to cytochrome $c$ on treatment of whole Micrococcus lysodeikticus organisms with lysozyme $20 \mu \mathrm{g} . / \mathrm{ml}$. Both cuvettes contained (in $3 \mathrm{ml}$. buffer); organisms equivalent to $0 \cdot 8 \mathrm{mg}$. dry wt.; cytochrome $c, 2$ mg.; KCN, 0.007 M. Experimental cuvettes contained also; A, lactate, $150 \mu$ mole; $B$, succinate, $150 \mu$ mole; $C$ and $D, N_{A D H}, \quad 0.255 \mu$ mole. Lysozyme $20 \mu \mathrm{g} . / \mathrm{ml}$. added to both cuvettes at $t=0$ in $A, B$, and $C$. D served as control showing that no reduction of cytochrome took place in absence of lysozyme. 
Bacillus megaterium can transfer electrons from $\mathrm{NADH}_{2}$ to ubiquinone-O in a system in which aerobic oxidation is blocked by $0.007 \mathrm{M}$-cyanide, with an activity of the order of $35 \mathrm{I}$.U./g. dry wt. On sonic treatment this activity increased to 90 I.U./g., and was not further increased by lysozyme treatment. When, however, whole bacilli were treated with lysozyme $(30 \mu \mathrm{g} . / \mathrm{ml}$.) the activity increased, roughly parallel with lysis, and to a value of 310 I.U./g. Continued contact with lysozyme up to $1 \mathrm{hr}$ caused only a slight loss in activity. Very similar results were obtained with menaquinone- $\mathrm{O}$ as electron acceptor.

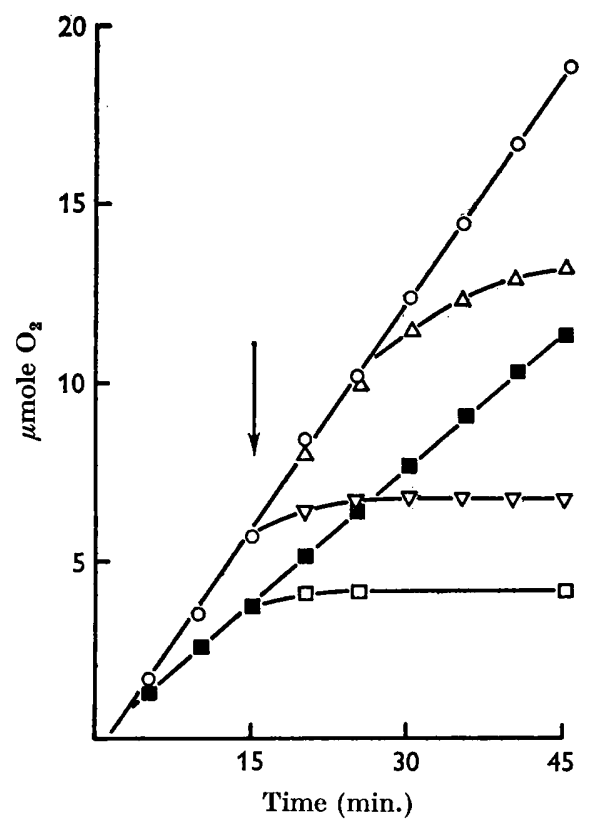

Fig. 7

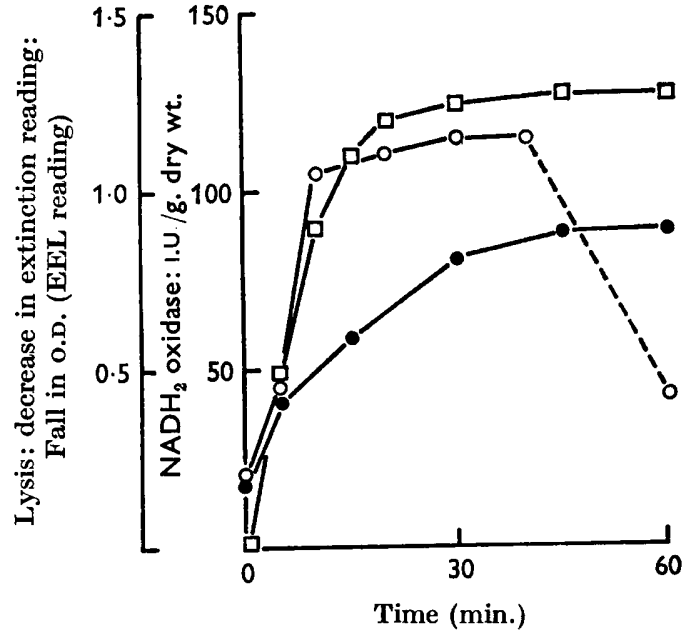

Fig. 8

Fig. 7. Effect of lysozyme on succinate oxidation and endogenous respiration in Bacillus megaterium. Manometers contained the equivalent of $6 \mathrm{mg}$. dry wt. organisms in $3 \mathrm{ml}$. buffer. $\square$, no additions (endogenous respiration; $\square$, lysozyme $33 \mu \mathrm{g} . / \mathrm{ml}$. added at $15 \mathrm{~min}$;, $0.05 \mathrm{~m}$-succinate; $\triangle$, lysozyme, $33 \mu \mathrm{g} . / \mathrm{ml}$. or $\nabla$ lysozyme $50 \mu \mathrm{g} . / \mathrm{ml}$. added at $15 \mathrm{~min}$.

Fig. 8. Development of $\mathrm{NADH}_{2}$ oxidase activity in suspensions of Bacillus megaterium following treatment with lysozyme $10 \mu \mathrm{g}$. $/ \mathrm{ml}$. $\bigcirc$ without sorbitol; $\odot$ in $1.5 \mathrm{M}$-sorbitol. $\square$ fall in extinction of suspension (without sorbitol) as index of lysis.

Effect of lysozyme on respiratory system in organisms which are not lysed

The following organisms were resistant to lysozyme in so far as no decrease in the turbidity of suspensions occurred when treated at the lysozyme concentrations stated: Bacillus subtilis, $1.5 \mathrm{mg} . / \mathrm{ml}$; B. mycoides and Proteus vulgaris, $0.5 \mathrm{mg} . / \mathrm{ml}$.; Sarcina lutea and Escherichia coli, 1.0 mg./ml.; Pseudomonas pyocyanea (aeruginosa), $\mathbf{0} \cdot 25 \mathrm{mg} . / \mathrm{ml}$. The lysozyme concentrations used were thus up to 1000 times greater than that which lysed Micrococcus lysodeikticus readily. Lysozyme was also allowed to act on sonically-treated suspensions of these organisms; again, no decrease in turbidity was observed, except for a $25 \%$ decrease with $\boldsymbol{P}$. pyocyanea.

Succinate oxidation by whole organisms was not affected by lysozyme treatment 
in Bacillus subtilis (Fig. 11 a), Escherichia coli (Fig. 11b), B. mycoides or Pseudomonas pyocyanea. The strain of Sarcina lutea used was apparently not able to oxidize succinate. Proteus vulgaris showed an appreciable increase in succinate oxidation on addition of lysozyme (Fig. 12). No action of lysozyme was observed on broken organisms, so it is presumed that some surface layer was being removed. This need not necessarily have been mucopeptide, since the $\beta$-glucosaminidase activity of lysozyme extends, for example, to chitin (Berger \& Weiser, 1957) and also possibly to some constitutent of the mucoids of hen-egg white (Meyer et al. 1936).

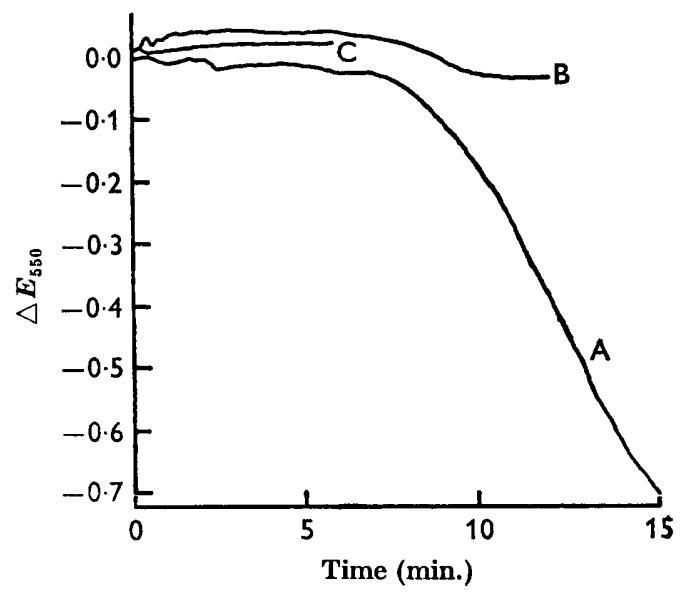

Fig. 9

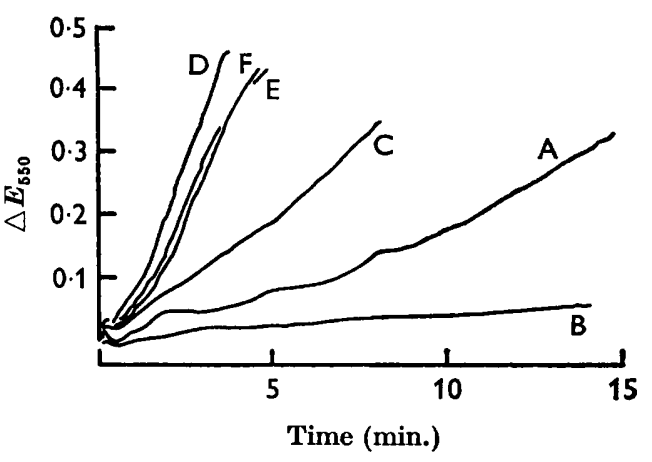

Fig. 10

Fig. 9. Cytochrome oxidase activity in lysozyme-treated Bacillus megaterium. Reference and experimental cuvettes contained (in $3 \mathrm{ml}$. buffer); equivalent of $1.8 \mathrm{mg}$. dry wt. organisms; also (Expt. A only) 1.5 M-sorbitol. Experimental cuvettes contained 2 mg. (mammalian) cytochrome $c$. Lysozyme $30 \mu \mathrm{g} . / \mathrm{ml}$. added at $t=0$ and decrease in $E_{550}$ recorded. A, sorbitol present; $B$, no sorbitol; $C$ buffer added in place of lysozyme.

Fig. 10. Reduction of (mammalian) cytochrome $c$ by lysozyme-treated sonically treated Bacillus megaterium. Reference and experimental cuvettes contained equivalent of $1.8 \mathrm{mg}$. dry wt. organisms, sonically treated for $2 \mathrm{~min}$.; cytochrome $c, 2 \mathrm{mg}$.; KCN, 0.007 $\mathrm{M}$; buffer to $3 \mathrm{ml}$. Experimental cuvettes contained also electron-donors : 0.05 $\mathrm{M}$-succinate $(A, D) ; 0.05$ M-lactate (B, E); $7.5 \times 10^{-5} \mathrm{M}^{-N_{A D H}}(\mathrm{C}, \mathrm{F})$. No change in $E_{550}$ was observed until addition $(t=0)$ of lysozyme $(20 \mu \mathrm{g} . / \mathrm{ml}$., A, B, C; $50 \mu \mathrm{g} . / \mathrm{ml} ., \mathrm{D}, \mathrm{E}, \mathrm{F})$.

The lysozyme-susceptible mucopeptide is believed to be present in many Gramnegative bacteria but at some distance below the surface of the organism. It was therefore thought possible that lysozyme might have an effect on broken organisms when it was not active against whole organisms. This was examined in Escherchia coli and Proteus vulgaris, since with the other organisms sonic treatment caused inactivation of the succinate oxidase system. With $\boldsymbol{P}$. vulgaris lysozyme did not affect the rate of succinate oxidation (Fig. 12); in $E$. coli (Fig. 11c) a slow inactivation was observed. In comparing these observations with the corresponding results for Micrococcus lysodeikticus (Fig. 3) it should be remembered that a 300-fold greater lysozyme concentration was used with $\boldsymbol{E}$. coli and $\boldsymbol{P}$. vulgaris.

None of the lysozyme-resistant organisms examined showed any appreciable $\mathrm{NADH}_{2}$ oxidase activity in whole organisms, and exposure to lysozyme (for $60 \mathrm{~min}$. at $37^{\circ} ; 17 \mu \mathrm{g} . / \mathrm{ml} .$, Bacillus subtilis, Escherichia coli, Proteus vulgaris; $33 \mu \mathrm{g} . / \mathrm{ml} .$, B. mycoides; $300 \mu \mathrm{g} . / \mathrm{ml}$. Sarcina lutea) did not expose any activity. 
Sonic treatment for $5 \mathrm{~min}$. (causing over $90 \%$ cell breakage) yielded $\mathrm{NADH}_{2}$ oxidase activities of 54 I.U./g. in B. subtilis, 105 in E. coli, 50 in B. mycoides, 16 in $P$. vulgaris and no activity in $S$. lutea. In the first two of these organisms exposure to lysozyme (conditions as above) caused slight loss in activity; $\boldsymbol{B}$. mycoides and $\boldsymbol{P}$. vulgaris were unaffected. No activity was developed in $S$. lutea. None of the organisms studied showed an increase in $\mathrm{NADH}_{2}$ oxidase activity at any stage of lysozyme treatment.

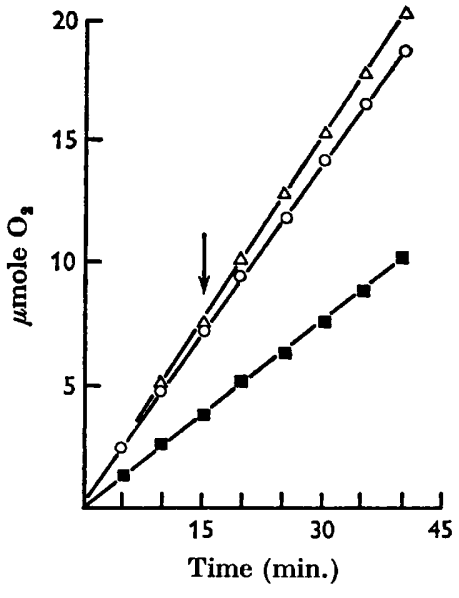

(a)

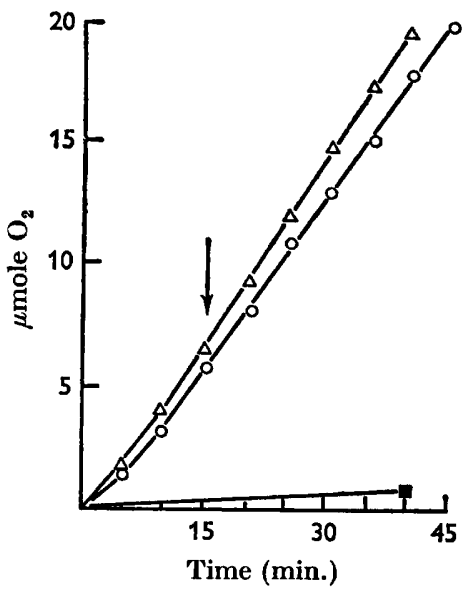

(b)

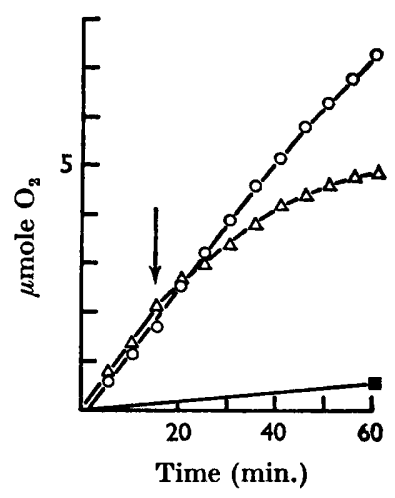

(c)

Fig. 11. Effect of lysozyme on succinate oxidation by whole organisms of $(a)$ Bacillus subtilis, equivalent to $9 \mathrm{mg}$. dry wt. organism; (b) Escherichia coli, equivalent to $10 \mathrm{mg}$. dry wt. organisms; and (c) $E$. coli equivalent to $10 \mathrm{mg}$. dry wt. organism subjected to 5 min. sonic treatment. $\square$, organisms suspended in (phosphate) buffer (endogenous respiration); $\bigcirc, 0.05 \mathrm{M}$-succinate; $\triangle, 0.05 \mathrm{M}$-succinate with lysozyme $0.5 \mathrm{mg} . / \mathrm{ml}$. added at $15 \mathrm{~min}$.

\section{DISCUSSION}

The present work confirms previous reports that bacterial respiratory systems are largely inactivated on lysis with lysozyme but suffer little or no damage when the cells are protected against lysis by addition of an osmotic stabilizer. It is well known that mechanical breakage of the cell (e.g. by sonic treatment, the Hughes press, or shaking with glass beads) can lead to severe loss of respiratory activity, and it might seem plausible that the action of lysozyme is only another form of mechanical breakage. Two factors suggest that the action of lysozyme is more subtle than this. (1) There is an appreciable time-lag between actual lysis of the organisms, and the loss of succinate oxidation. (2) Succinate oxidation which has survived sonic breakage of the organisms is destroyed by lysozyme. This might suggest that the cell membrane (if we assume the latter to be the site of the oxidizing enzymes) is embedded within the cell wall rather than lying between the cell wall and the cytoplasm, as is generally believed (see Salton, 1964). Alternatively, we might assume that the cell membrane is stuck firmly to the cell wall; when the cell is mechanically disrupted, this attachment will allow a portion of the membrane material, at least, to retain its morphological integrity despite exposure to a hypotonic medium. Lysozyme treatment would then remove this mechanical protection. 
The concept of a respiratory system embedded in cell wall (or at least in some lysozyme-sensitive material) is supported by the results of the experiments with $\mathrm{NADH}_{2}$ oxidase. Removal of the cell wall without lysis (by lysozyme treatment in presence of sorbitol) allows access of $\mathrm{NADH}_{2}$ (and also cytochrome $c$ ) to the respiratory system. The cell wall thus appears as an organ of selective permeability as well as a mechanical structure. Sonic disintegration exposes only a

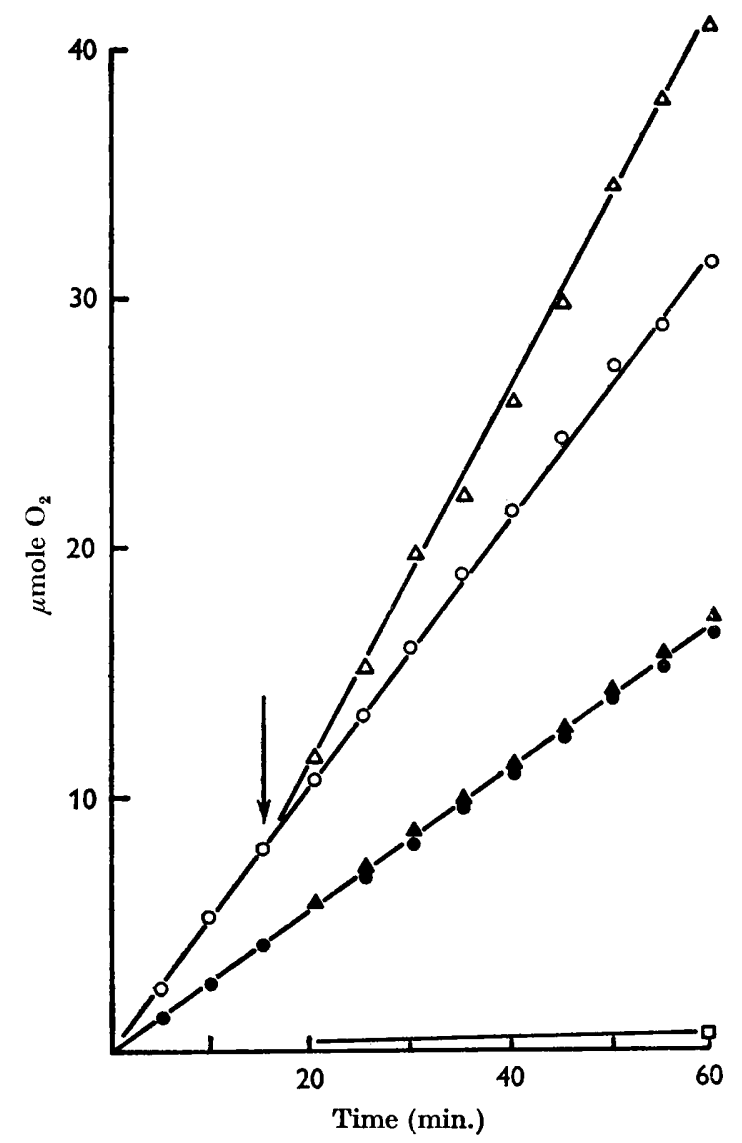

Fig. 12. Action of lysozyme on succinate oxidation in Proteus vulgaris. Each manometer contained equivalent of $7.5 \mathrm{mg}$. dry wt. organism (whole, or sonically treated for $5 \mathrm{~min}$.) in $3 \mathrm{ml}$. buffer. $\square$, no additions (endogenous respiration); $0, \bullet 0.05 \mathrm{M}$-succinate, with whole or sonically treated organisms respectively; $\triangle, \Delta ; 0.05 \mathrm{~m}$-succinate with addition of lysozyme $0.5 \mathrm{mg}$. $/ \mathrm{ml}$. at $t=15 \mathrm{~min}$., whole or sonically treated organisms, respectively.

fraction of the total potential $\mathrm{NADH}_{2}$ oxidase; greater activity is attained by lysozyme treatment of the sonically-fragmented material. The oxidase system must be either' embedded in 'cell wall', or accessible to $\mathrm{NADH}_{2}$ only from its outer aspect. The report by Cole \& Hughes (1965) that ATPase activity in Lactobacillus arabinosus was released on prolonged sonic treatment, to a much higher degree than that obtained merely by breaking of the organisms in the Hughes press, presents an analogy with our findings.

Ability to react with cytochrome $c$ after lysozyme treatment is also of some interest 
in view of the almost uniformly negative results obtained on numerous occasions when bacteria or bacterial extracts have been examined for 'cytochrome oxidase' (see Smith, 1954, 1961). The highest reaction rates obtained in the present studies with Micrococcus lysodeikticus were of the order of 30 I.U./g. (based on two-electron transfer; data calculated from Figs. 6 and 7) compared with figures of the order of 150 I.U./g. for $\mathrm{NADH}_{2}$ or succinate oxidation. It is possible, however, that we had not achieved the conditions for maximal cytochrome $c$ reaction.

Lysozyme ultimately inactivated the $\mathrm{NADH}_{2}$ oxidase system in disintegrated or lysed organisms though the loss of activity was much less rapid than with succinate oxidase. It is not possible to decide whether the respiratory systems possess lysozyme-sensitive components, or whether the membrane itself is liable to osmotic destruction as distinct from the lysis of the organism. Suspensions of broken organisms can retain their oxidase activities after treatment with lysozyme in presence of osmotic stabilizers; but loss of activity will occur when lysozyme is added at concentrations much in excess of that required for lysis.

Treatment of the lysozyme-insensitive organisms, even with relatively high concentrations of lysozyme, neither inhibited succinate oxidation nor enhanced $\mathrm{NADH}_{2}$ oxidase. In only one case did lysozyme produce (in an organism which it did not lyse) effects comparable with those obtained with Micrococcus lysodeikticus or Bacillus megaterium; this was the inhibition of succinate oxidation on treatment of broken Escherichia coli with lysozyme. No effect was observed with whole $\boldsymbol{E}$. coli organisms, so this is consistent with the idea that Gram-negative bacteria possess a layer of the lysozyme-sensitive mucopeptide located at or near the inner surface of the cell wall (Salton, 1964).

\section{REFERENCES}

Berger, L. E. \& Weiser, R.S. (1957). The $\beta$-glucosaminidase activity of egg-white lysozyme. Biochim. biophys. Acta, 26, 517.

Cole, H. A. \& Hugnes, D. E. (1965). The enzymic activity of the outer shell of Lactobacillus arabinosus. J. gen. Microbiol. 40, 81.

Hogeboom, G. H., \& Schneider, W. C. (1952). Cytochemical studies; physical state of certain respiratory enzymes of mitochondria. J. biol. Chem. 194, 513.

Horecker, B. L. \& Kornberg, A. (1945). Extinction coefficients of the reduced band of pyridine nucleotides. J. biol. Chem. 175, 385.

Meyer, K., Palmer, J. W., Thompson, R. \& Khorazo, D. (1936). On the mechanism of lysozyme action. J. biol. Chem. 113, 479 .

Pandya, K. P. (1963). Quinones and electron transport in bacteria. Ph.D. Thesis : Liverpool.

Salton, M. R. J. (1953). The composition of the cell wall of some Gram-positive and Gramnegative bacteria. Biochim. biophys. Acta, 10, 512.

SAlton, M. R. J. (1964). The Bacterial Cell Wall. Amsterdam: Elsevier Publishing Co.

SмIтн, L. (1954). An investigation of cytochrome $c$ oxidase activity in bacteria. Archs Biochem. Biophys. 50, 315.

SмIтH, L. (1961). Cytochrome systems in aerobic electron transport. In The Bacteria. Ed. by I. C. Gunsalus, \& R. Y. Stanier, Vol. 2, p. 365. New York: Academic Press.

Weibulu, C. (1953). The isolation of protoplasts from Bacillus megaterium by controlled treatment with lysozyme. $J$. Bact. 66, 688.

Weibull, C. (1956). Bacterial protoplasts; their formation and characteristics. In Bacterial Anatomy, Symp. Soc. gen. Microbiol. 6, 111.

Wiame, J. M., Strock, R. \& Vanderwinkel, E. (1955). Biosynthèse induite d'arabokinase dans les protoplasts de Bacillus subtilis. Biochim. biophys. Acta, 18, 353. 